\title{
Translanguaging in kasi-taal: Rethinking old language boundaries for new language planning
}

\author{
Leketi Makalela \\ Wits School of Education, University of the Witwatersrand, South Africa \\ E-mail: Leketi.Makalela@,wits.ac.za
}

\begin{abstract}
This paper examines discursive language practices among Black township natives who consider kasi-taal, a hybrid urban variety from major Black townships in Johannesburg, their home language. Firstly, an analysis of 20 dialogue samples that were collected from second-year university students from five townships reveals that traditional linguistic boundaries between indigenous African languages have been re-negotiated to express expanded views of the self. Secondly, the study shows that expansion of linguistic codes is enhanced by common substrate systems in the Nguni and Sotho languages, lexical borrowings, semantic shifts and morphological derivations from Afrikaans and English as source languages. Using a translanguaging framework, I argue that kasi-taal languaging practices challenge traditional conceptualisations of language and provide a window into future possibilities for merging African languages. Implications for future research based on the study's findings are highlighted at the end of the paper.
\end{abstract}

Keywords: translanguaging, hybridity, kasi-taal, language boundaries, townships

\section{Introduction}

It is almost axiomatic that traditional language boundaries in highly multilingual and hybrid communities are increasingly blurred as new discursive linguistic resources emerge (Blommaert 2010, Garcia 2011, Creese and Blackledge 2010). Both migration patterns towards the developed countries and translocal movements that are facilitated by rapid urbanisation have created new sites of linguistic and identity negotiation in the $21^{\text {st }}$ century, which characterise what Blommaert (2010) refers to as a "critical sociolinguistics of globalisation". A plethora of studies that are framed within translanguaging - a new approach to understanding multilingual speakers' use of more than one linguistic code in their everyday way of speaking - has shown that mobile linguistic resources are exerting pressure on monolingual practices and ideologies world-wide (Baker 2011, Blommaert 2010, Creese and Blackledge 2010, Shohamy 2006). While translanguaging encompasses instances of code-switching in language contact situations, it differs from traditional conceptions of codeswitching in that the starting point is not language as an autonomous skill. Rather, the starting point is what the speakers do and perform with their 
mobile and flexible discourse practices (Garcia 2009). Surprisingly, there is a paucity of research on hybrid language forms as well as on the points of view of the speakers in complex multilingual contexts.

South Africa has experienced a new wave of mobility, which started with the new sociopolitical dispensation of 1994 that precipitated freedom of movement within its borders. The majority of these movements were seen in the urban centres to which local migrants flocked to eke out a living, in the process deserting the former Bantustan homelands in the rural areas. Beyond this, there have also been a large number of migrants from neighbouring African countries such as Zimbabwe, Mozambique, Lesotho, Swaziland and Botswana. The first port of entry for both local rural migrants and immigrants from countries outside of South Africa has always been the Black townships. Necessarily, this unprecedented immigration expanded the traditional bases of the townships, which were geographically and linguistically demarcated prior to 1994. The result has been that a typical Black township, also referred to as ekasi in this study, has become a new site of linguistic contact between linguistic communities that were separated from one another during the apartheid era. For example, most sections of Soweto were initially separated according to language differences (e.g. Shiawelo for Xitsonga and Mzimhlophe for isiZulu speakers). When framed in this light, it follows that South Africa becomes a microcosm of superdiversity with spatio-temporal complexes that define global movements of the $21^{\text {st }}$ century (Blommaert 2010, Mignolo 2000).

Sociolinguistic research that describes Black township hybrid language forms has provided an extensive account of language use under labels such as Flaaitaal, Tsotsitaal and Iscamtho (Glaser 1991, Makhudu 2002, Ntshangase 2002, Slabbert and Myers-Scotton 1996). Flaaitaal, which means "street-" or "smart language", and Tsotsitaal, which means "language of a thug", have been used interchangeably to refer to a mixture of African languages and Afrikaans in the 1950 s, and were largely seen as language forms used by male criminals in the underworld. Later, these languages were used in resistance and defiance campaigns against the apartheid government (Glaser 1991). Iscamtho, on the other hand, is derived from Nguni language groups (later used by Sotho language groups) to describe a hybrid language of the Amalaita criminal network in the early 1900s (Makhudu 2002, Ntshangase 2002). Different from Flaaitaal/Tsotsitaal, Iscamtho emphasises the mixture of African languages in use. Over time, both urban varieties were re-appropriated by their users as markers of urban identity and of being street-wise. The differences between these forms are increasingly disappearing as can be seen in an example such as heitha, as in heitha Comrade Madiba (Makhudu 2002, Ntshangase 2002). Whereas linguistic analyses of these varieties have been documented, to date, interpretations have been confined within the premise of languages as sets of autonomous skills. In this paper, I use the label "kasi-taal" to refer to evolved forms of both Iscamtho and Flaaitaal/Tsotsitaal in order to account for weakening boundaries between Sotho, Nguni, Afrikaans and English language forms and to understand how its speakers, who claim kasi-taal as their home language, redefine their identities. Therefore, kasi-taal, which means a language of the location or township, is preferred to emphasise weakening boundaries between languages in space rather than to refer to a social behaviour as the previous labels suggested. I examine kasi-taal's complex linguistic development through dialogues of university students who are residents of five townships within the vicinity of Johannesburg. Using the translanguaging framework described above, I argue that current kasi-taal practices reflect heteroglossic speech where rules and norms overlap traditional language boundaries and, because of this, they 
provide a window into future linguistic mergers and a way of understanding the expanding linguistic identities of Black South Africans from the townships.

\section{Sociolinguistics of mobility}

Increased movements of people between and within nation states in the $21^{\text {st }}$ century have correspondingly resulted in movements of languages and shifting of traditional boundaries (Makoni and Pennycook 2007, Makoni and Mashiri 2007, Creese and Blackledge 2010). This new development has spurred interest among sociolinguists who started shifting their attention to language and mobility in superdiverse communities. The concept 'superdiversity' was originally used to refer to European communities that have recent immigrants with diverse linguistic and cultural backgrounds in spaces that have existed for fewer than 10 years. However, Creese and Blackledge (2010:550) remind us that this new diversity is not limited to

[...] new migrants who arrived in the last decade, but includes changing practices and norms in established migrant (and non-migrant) groups, as daughters and sons, grand-daughters and grand-sons, great-grand-daughters and great-grand-sons of immigrants (and non-migrants) negotiate their place in their changing world.

In this new context of superdiversity, the intermeshing and interweaving of a number of factors creates a post-migration experience that sets aside regional, ethnic, cultural and linguistic characteristics of particular groups in favour of a more hybrid habitus (Heller 2007).

To describe multilingual practices in the post-migration communities, some sociolinguists discredit treatment of languages as hermetically-sealed units in favour of weakening boundaries between traditional linguistic codes and the use of discursive linguistic resources in functionally integrated ways (see Makoni and Mashiri 2007). To this end, a large body of scholarship has identified globalised communication practices as those involving a constant merger of translocal, transcultural and transnational use of languages when multilinguals engage in their everyday ways of meaning-making and identifying in their new settlement spaces (Blommaert 2010, Heller 2007, Hornberger and Link 2012). This includes new language inventions. Accordingly, this new type of communication is best explained as spatio-temporally complex as one language can no longer be tied to space and time. Here, multilingual speakers are engaged in a negotiation of multiple identities which cut across traditional language boundaries, and keep making choices in defining who they want to become (Garcia 2009, 2011). This global languaging trend thus calls for detailed research on linguistic complexity in local situations under the notion that can best be described as "the sociolinguistics of mobility".

\section{Translanguaging practices}

The sociolinguistics of mobility frames the notion of 'translanguaging' which is used to describe the complex sociolinguistic realities of multilingual speakers who shift between languages in different contexts (Garcia 2011). Translanguaging began in Wales in the early 1980s as a pedagogic practice to reinforce skills in both English and Welsh. According to Baker (2011), the term "trawsieithu" (translanguaging) means a pedagogic practice where one receives input in one language and gives output through the medium of another language in order to maximise learning, promote fuller understanding of the subject matter, and help 
develop the weaker language. This practice has increasingly caught the imagination of educational linguists about the prospects of using two or more languages in the same lesson and, in this way, moving away from the negative $20^{\text {th }}$ century idea that learning or using more than one language causes mental confusion (Baker 2011, Lindholm-Leary 2001).

Classroom translanguaging has been studied in various parts of the world as a new framework that shifts the focus from cross-linguistic influence to how multilinguals intermingle linguistic features that are assigned to a particular language (Hornberger and Link 2012). Well-known studies were conducted in schools in the United Kingdom (UK) to assess the pedagogic efficacy of translanguaging in multilingual classrooms. Separate studies by Creese and Blackledge (2010) and Wei (2011) have found that allowing students to use their linguistic resources creates positive experiences at school and maximises pedagogic and cognitive benefits. In South Africa, emerging studies by Madiba (2013) and Makalela (2013) have shown cognitive advantages in literacy and language classes at two tertiary institutions, namely the University of Cape Town and the University of the Witwatersrand.

Beyond the classroom, which is not the focus of this paper, translanguaging has been extended to include all discursive resources that apply among multilingual speakers in their everyday way of communicating (Garcia 2009). Outside of the classroom, translanguaging research has dealt with cognitive, contextual and cultural aspects of multilingual communication (Baker 2011). Black townships in Johannesburg are an embodiment of translanguaging practices outside of the classroom. Since the dawn of the new political dispensation in 1994, more Black communities have moved into townships in Johannesburg in search of better living conditions. As stated earlier, a large portion of these movements comprised people from former Bantustan homelands that were linguistically separated and a new wave of migrants from member states of the Southern African Development Community (SADC). It is noteworthy, however, that there is a dearth of research that investigates translanguaging outside of the classroom to assess the cognitive and social dimensions of multilingual speakers.

\section{The study}

This is an exploratory study that relies on data from university students who live in the Black townships around the city of Johannesburg. Since kasi-taal is relatively neglected in the literature, an exploratory study was deemed necessary to unearth theory from the data instead of testing hypotheses around a well-known phenomenon (cf. Babbie 2007). In this preliminary stage, the study uses secondary information from self-induced dialogues in an educational context rather than from a natural setting. The study forms part of an ongoing research project that seeks to explain and interpret translanguaging practices among multilingual speakers in South Africa. This particular study is guided by the following questions:

1. How do students from superdiverse townships use language?

2. What are the characteristic features of their translanguaging speech forms?

\subsection{Participants}

The participants in the study are $20(\mathrm{n}=20)$ second-year students who were enrolled in a language-in-education class for student teachers at the University of the Witwatersrand's School of Education. There were 12 females and 8 males with a mean age of 19.1 years $(\mathrm{M}=$ 
19.1). Their geographical spread showed a distribution profile of five major townships around Johannesburg: Soweto, Alexandra, Tembisa, Katlehong and Daveyton, as shown in Table 1 below.

Table 1. Participant summary

\begin{tabular}{|l|l|l|l|}
\hline Name of ekasi & $\begin{array}{l}\text { Number of } \\
\text { speakers }\end{array}$ & $\begin{array}{l}\text { Number of } \\
\text { languages }\end{array}$ & $\begin{array}{l}\text { Gender } \\
\text { (F=female; } \\
\text { M=male) }\end{array}$ \\
\hline Soweto & 6 & 11 & $3 \mathrm{M} ; 3 \mathrm{~F}$ \\
\hline Tembisa & 5 & 12 & $4 \mathrm{~F} ; 1 \mathrm{~F}$ \\
\hline Alexandra & 4 & 13 & $2 \mathrm{~F} ; 2 \mathrm{M}$ \\
\hline Daveyton & 2 & 11 & $1 \mathrm{~F} ; 1 \mathrm{M}$ \\
\hline Katlehong & 3 & 12 & $2 \mathrm{~F} ; 1 \mathrm{M}$ \\
\hline
\end{tabular}

Soweto was represented by six participants who reported that they had exposure to all 11 of the official languages in South Africa. In this subsample, there was an equal representation of male and female participants (3F; 3M). Tembisa had five participants who reported having been exposed to at least 12 languages (here, they made a distinction between Shangaan in Mozambique and Xitsonga in South Africa). Alexandra had five participants with a total of 13 languages spoken in the townships, while Daveyton and Katlehong had two and three participants with exposure to 11 and 12 languages, respectively.

Eighteen out of the 20 participants reported that their mother tongue was kasi-taal, a hybrid form of many languages that includes Afrikaans, English, Nguni (isiZulu, isXhosa, isiNdebele, and Siswati) and Sotho (Sepedi, Setswana and Sesotho) languages. They did not see identifying any of the nine indigenous African languages as a mother tongue as suitable for their complex language backgrounds. The majority of the participants acquired the languages before the age of six, and they already spoke at least three languages fluently by the time they started primary school. Their participation in the study was the result of a purposeful sampling technique that used belonging to or having their homes in the townships as a selection criterion. It was expected that they would form an ideal group of participants to provide rich information about language practices in these areas. These participants had exposure to almost all of the 11 official languages of South Africa as well as cross-border varieties of Sotho (Lesotho, Botswana), Nguni (Swaziland, Zimbabwe) and Tonga (Mozambique) languages.

\subsection{Data collection}

Data for this study comprised 20 self-recorded dialogues that occurred outside of the classroom. All 60 students who enrolled for the language-in-education class were asked to organise themselves into pairs and use their cellular phones to record at least three separate interactions as part of their final assignment for the course. A simple random selection of one dialogue set from each submission was carried out for marking, which was followed by a purposive selection of 20 dialogues representing township experiences or speech patterns. After the students who produced the selected dialogues agreed to have their dialogue texts reviewed and used for research purposes, they filled out consent forms and provided additional background information to help the researcher to classify and interpret the data. 


\subsection{Analysis}

After the dialogues were transcribed and checked for accuracy by the participants, the dialogues were read twice by three independent readers with knowledge of the majority of the indigenous African languages and experience of township life. Themes from the dialogues were extracted using a universal reductionist approach (i.e. an analytic procedure that starts from broad categories of a phenomenon and reduces it to its smallest components) until saturation points were reached for each of the identified themes. The second phase of the analysis was discoursebased, focusing on instances of language mix or shift to identify and develop patterns of hybridity within and between utterances or thought units. The utterances were quoted to support the main themes observed throughout the conversations.

\section{Results}

The results of the study are organised into six themes: linguistic flexibility, social sensitivity, imagined communities, multi-greetings, merged Sotho varieties and convergences between Sotho and Nguni varieties.

\subsection{Linguistic flexibility}

The results of the study showed that kasi-taal speakers have an extended repertoire of languages that they pool together to fit their communication needs. They displayed linguistic flexibility, which suggests a case of versatile intermingling of language resources rather than static and separated codes. Extract 1 shows this flexibility:

\section{Extract 1}

A: Ai baba. Yini ngawe? What is your problem? Hawu!

B: Maybe you are right man, yazi.

Here, Speaker A begins the conversation in isiZulu when emphatically responding with Ai baba for "hey man". Characteristically, baba means "father", but it is used in this case as a token of endearment. The question "What is your problem?" is preceded by its isiZulu version, yini ngawe, and followed by another isiZulu surprise marker, Hawu! Then Speaker B responds to the previous point (not in the script) in English and isiZulu within the same utterance: Maybe you are right, yazi (you know). This conversation shows a typical case where two multilingual speakers choose discursive resources from different languages to communicate and carry out social functions. Speaker A processes a stream of thoughts by alternating languages within a short utterance. However, the order of the input towards Speaker B is not reciprocated. Instead, Speaker B gives his output in English and then isiZulu - something that typifies a translanguaging practice. In Speaker B's utterance, the languages are intermeshed in the same unit of meaning. This means that the Nguni tag, yazi ("you know") adds meaning to the previously-stated thought. Overall, this conversation shows that kasi-taal speakers have a language repertoire that breaks boundaries in ways that render them versatile speakers and listeners. 


\subsection{Social sensitivity}

In contrast to conversations between two multilingual speakers who share the same linguistic repertoires, the data revealed that multilingual speakers are sensitive to the conversation spaces they occupy. Extract 2 is a prototypical example:

Extract 2:

C: How about you teach me isiZulu and I help you guys with English?

D: Deal baba yo. What do you say Siboniso? Le auti ingasinceda mfana, this guy can help us.

This is a conversation between two kasi-taal speakers and an English native speaker at a university campus. The native speaker (Speaker C) offers to teach the kasi-taal students English in return for them teaching him isiZulu. Speaker C uses a monolingual utterance since English is the only language he knows. In response to C, Speaker D starts talking in English, meshed with isiZulu, baba yo. This speaker agrees to C's proposal in English, but the feeling of gratitude is expressed in an isiZulu phrase used to show endearment to a male figure, baba. This gratitude is interrupted in the following stream of thought where the speaker asks his friend Siboniso if he also agrees to be helped and to reciprocate by helping the English native speaker. This part of the information flow is mediated through English to accommodate the English monolingual speaker. The next meaning unit is expressed in isiZulu, le auti ingasinceda mfana, which is subsequently repeated in English, "this guy can help us". This shows that Speaker D is sensitive to other speakers around him, directing his talk to one speaker, but ensuring that the bystanding hearer is part of the conversation. From the point of view of the speaker, we can see that he draws on different linguistic resources available to him to think about and accommodate complex linguistic situations around him. This tallies with general observations elsewhere that multilingual speakers are complex users of language and that they are socially sensitive to others (cf. Canagarajah 2011, Wei 2011). Their heightened sensitivity reveals that multilinguals are capable of acting as monolinguals and that they take up different identities in a singular or multilayered fashion, if and when the situation requires them to behave in either way.

\subsection{Imagined communities}

The notion of 'imagined communities' is used in language and identity studies to refer to desired membership of groups of people to which we connect through the power of imagination (cf. Kanno and Norton 2003). This membership includes using identity markers and approximating the behaviour of the imagined community. The data has shown that kasi-taal speakers do not only use vocabulary from local contexts; they also draw from transnational cultural expressions with which they identify. The following extract shows this trend:

\section{Extract 3 \\ E: Ey dwang, you see uyaphapha \\ F: You can't say that about my sister nigger.}

First, Speaker E uses a slang term, $d$ wang, which refers to a guy. In the same utterance, he brings in English and isiZulu within the same stream of thought, you see uyaphapha (you see, you are so inquisitive). Speaker E, on the other hand, swears at him using the word nigger, which was historically used to refer derogatively to African Americans and then re-appropriated 
by this group of speakers to refer to a friend in a pledge of solidarity (Smitherman 2000). This imported usage shows that kasi-taal speakers often have imagined communities due to international exposure to different cultures and behaviours. While they localised their linguistic repertoires, they also develop transcultural repertoires that cut across national boundaries as part of their expanded ways of seeing themselves in relation to others in the $21^{\text {st }}$ century. It is in this context that Blommaert's (2010) concept of a 'critical sociolinguistics of globalisation' becomes relevant. In this case, kasi-taal speakers are not only preoccupied with local ways of identifying, but they also assume transcultural identities that are mediated through globalisation.

\subsection{Multi-greetings}

The data revealed numerous ways of passing on greetings in the townships. The following extract reveals such greeting complexities:
Extract 4
G: Sho sho mfana
H: Hey
G: Zthini daso
$\mathrm{H}$ : Am at the top of the mountain, yourself
G: Nami ngigrand
$\mathrm{H}$ : Any plans for the weekend?
G: You know with me abantwana
$\mathrm{H}$ : I thought as much, some people
$\mathrm{G}:$ Hawu uthini manje?
$\mathrm{H}$ : Hey did you find ...
G: Who are some people
$\mathrm{H}$ : Wow is that ...
G: Don't play smart here. Just answer the question.
$\mathrm{H}$ : Question ... what question?
G: Nar sharp

Greetings and goodbyes have taken blended language forms among the kasi-taal speakers in this dialogue. Sho, a shortened version of English "sure", is used informally to start a conversation such as when greeting someone. Speaker G says, "sho sho mfana", using the word mfana for "boy", a term of endearment for a young male person as used, for example, in the name of the national soccer team "Bafana Bafana". Speaker H responds in English, while Speaker G continues to speak in kasi-taal, by asking zthini daso?. This utterance shows a blend of isiZulu (zthini for "how are things?") and a shortened Afrikaans version (daso for "daar so" which means "there"). It is worth noting that Speaker H is speaking exclusively in English, while Speaker G sticks to the Nguni language repertoires at his disposal. At the end of the conversation, Speaker $\mathrm{G}$ is unhappy with $\mathrm{H}$ and uses sharp, which is commonly used to mean either "goodbye", "I don't care", "okay" or "I am fine". What is striking about these usages is that both sharp and sure have evolved semantically from English meanings ("sharp" as in "a sharp knife" and "sure" which means "certain") to localised forms used by the kasi-taal speakers, as seen in this dialogue. The overall conversation style for building social rapport in this dialogue typifies translanguaging practices where input is received in one language and output is given in a different language. Here, we see an exchange of input and output languages 
between the speakers who share common, multi-layered linguistic repertoires. Here again, multilinguals use flexible, sensitive and complex discourses to fit their social needs.

\subsection{Merged Sotho language varieties}

One of the distinguishing characteristics of the dialogues is the mixed use of languages in the Sotho cluster (Setswana, Sepedi, Sesotho) as in the following extract:

\section{Extract 5}

I: Eh matjita, I really have to tell you guys iets

$\mathrm{J}$ : He banna bolela monna o ska tlo te ketsa ngwanyana (Oh my, talk, don't behave like a girl)

I: Hahaha this guy is on some gay trip hey

$\mathrm{J}$ : hahaha, niks matjita, no homo (US Cartoon). Ere... < laughing > nothing guys, I am not a gay.

I: Ok, tell us then

$\mathrm{J}$ : I've got this thing for this girl I met at school. Her name is Katy

I: Ahh o sa re bjalo jo, byanong. O tlo mo shela neng? (Don't say this now. When are you going to ask her out?)

J: I actually don't know hey

I: No dude, o ra bjanong? (what do you mean now?)

J: She doesn't know. What she knows ke gore we are friends and that's that.

First, this extract shows another typical translanguaging practice where languages of input and output are exchanged. In this case, there is an extensive use of Afrikaans vocabulary like niks ("nothing") and iets ("something") shared between speakers I and J. Secondly, a mixed version of three Sotho languages (Sesotho, Sepedi, Setswana) is used by both speakers in all instances where they give or receive input in English. The sentence He banna bolela monna o ska tlo te ketsa ngwanyana shows that the speaker has used three languages in one utterance. He starts with Sesotho, he, followed by banna ("men") that is commonly shared among the three languages; bolela ("speak") is Sepedi; o ska tlo te is a hybrid form; ketsa is Setswana, and ngwanyana is in both Setswana and Sesotho. A denser mixture is found when Speaker I says Ahh o sa re bjalo jo, byanong. O tlo mo shela neng? where it is hard to tease out parts of the sentence into any of the languages, partly because these languages are mutually intelligible and partly because of the hybrid mix which this speaker has used. $O$ ra bjanong is found in both Setswana and Sesotho, slightly deviating from the Sepedi version of O ra bjang?

As observed in this extract, the speakers are still capable of separating one language form from another when it is communicatively meaningful for them to do so. In the last utterance, Speaker $\mathrm{J}$ selects a typical Sepedi form ke gore, instead of the Setswana/Sesotho version ke hore, which might imply that Speaker J's preferred variety of Sotho is Sepedi where the voiceless alveolar fricative [g] is used in the place of [h]. This extract reveals that the Sotho languages are mutually intelligible even though certain phonological divergences are observed between the varieties (see Alexander 1989, Makalela 2009, Nhlapho 1944 on the harmonisation proposal). In terms of everyday dialogues, speakers of kasi-taal concomitantly exploit these intelligibility patterns to transcend boundaries in the Sotho cluster. 


\subsection{Convergences between Sotho and Nguni}

Apart from the blended use of Sotho languages as seen in Extract 5, the participants' discourse patterns reveal a further layer of complexity, which suggests an internal organisation rule that feeds into translanguaged forms. This was observed even in instances where Sotho and Nguni languages were mixed and used interchangeably. Extract 6 below is revealing in this regard:

Extract 6:

$\mathrm{K}$ : Hey bro awungimele da. (Wait for me there.)

L: Eish ntwana re ka bloma kae? ( ....my friend where should we sit)

$\mathrm{K}$ : A si blome ecafeteria after lelecture, ngifuna nje ukugawula (Let's sit at the cafeteria after the lecture; I would like to eat)

L: Ei bro, did you get what the brother was talking about? Iyo, the die man o a bora tjo (... is man is boring...)

$\mathrm{K}$ : Tjo le muntu u ya confusa, one minute o ringa ngabo Bandura, the next $u$ ringa ngaboZuma (... this person is confusing; one minute he speaks about Bandura and the next one he speaks about Zuma)

L: Ya parliament le ditheorist di mixana kae? (Where do the parliament and theorist mix?)

K: Eintlik die man othole le degree yakhe waar? It must be from e Pick'n Pay or Shoprite (Actually, where did this man get his degree?)

L: O utlwile voice ya hae nkare ke Spanish guitar, iyo ka hopola Toni Braxton a shapa guitar. (You heard his voice is like a Spanish guitar ... I thought about Toni Braxton playing a guitar)

K: It's like okhanywe ngamarula (It's like he's strangled by a marula fruit)

L: Eish nayi lentwana yemlungu iyankinya, ithanda uku answer during ama lecture and asking ama question a dumm i sho off yona tjo (... and this white chick likes to answer the lecturers and asking stupid questions. She's showing off)

This extract shows its kasi-taal blend with the use of Afrikaans forms, da for daarso ("there"), eintlik for "actually", waar for "where" and die man for "the man", which are shared between speakers in this dialogue. Two particular phrases that are distinctly kasi-taal are a si blome and ukugaula. The former has an Afrikaans root, blom for "flower" (noun), but has been affixed with a Sotho/Nguni verb marker -e, to convert it into a verb, which means "to sit". This usage shows complexities of both semantic shifts and derivational morphology procedures where one part of speech is changed into another. The same derivational use of words across languages is found in the word ukugaula, which is derived from the English noun "gaol". In this example, it has taken the Nguni infinitive pre-verbal affix $u k u$ - to turn it into a non-finite verb meaning "to eat". This is derived from the hurried manner in which black prisoners were expected to eat in jails (information elicited from a personal conversation with an adult kasi-taal speaker). When this happens between languages, one sees the creative use of the hybrid form by kasi-taal speakers as rule-overlapping. I refer to this phenomenon of rule-crossing between languages as "internal translanguaging".

The extract reveals more extensive affixation from Nguni languages, with ama-, $e$ - (as in ecafeteria) and le-(as in lelecture), and from Sotho languages, with di- (as in ditheorist), which is a Noun Class Prefix 4 common to all these languages. This shows an initial phase of lexical borrowing where speakers of African languages use underlying forms to shape new words to 
be added to their lexical pool. Through translanguaging within Nguni and Sotho languages, this borrowing from outside of African languages harmonises vocabulary development. For example, ecafeteria becomes a lexical item that could belong to all Nguni languages (isiXhosa, isiZulu, isiNdebele and Siswati). Similarly, ditheorist cannot be confined within traditional Sotho language boundaries (Sepedi, Sesotho and Setswana). It is evident from this example that kasi-taal, through its extensive lexical borrowing, has invariably broken the traditional boundaries between these languages. What follows logically is that as more words are borrowed into one's kasi-taal repertoire, they are morphologised according to the structure of Nguni or Sotho languages. In this regard, internal translanguaging logic between languages in the same cluster makes their mutual intelligibility very apparent.

In a nutshell, we see mutual intelligibility through the exchange of vocabulary items between the languages (external translanguaging) and through the retention of the common morphological forms on newly borrowed words (internal translanguaging), which resembles most language contact situations (cf. Gumperz 1982, Mesthrie 2002). The latter is further demonstrated by words such as confu-sa from "confuse" and mix-ana from "mix". Several studies on codeswitching in Flaaitaal and Iscamtho have also shown this type of grammaticalisation (Ntshenganse 2002, Makhudu 2002) but, for purposes of this study, one observes that kasi-taal recognises no boundaries between and within languages, and speaker mobility from Nguni to Sotho versions and vice-versa seems a natural way to communicate for the participants in this extract.

\section{Discussion}

This study sought to explain how kasi-taal speakers perform their multilingual practices in the townships around Johannesburg. The main finding from the self-recorded dialogues is that communication among these speakers is spatio-temporally complex and it embodies the transcultural and linguistic movements of people who cohabitate in the ekasi (location) space. Their linguistic moves cut across traditional linguistic boundaries in ways that reflect their multiple identities and hybrid habitus.

The first instance of translanguaging practices was found in the speakers' ability to mesh codes within single thought units. For example, there were opportunities to use more than three languages in one utterance. This linguistic flexibility suggests that multilingual speakers in the ekasi spaces described above do indeed have an extended linguistic repertoire from which they extract a range of language forms in order to express meanings. As this process of relating meaning in enmeshed codes has been automatised, one is able to affirm a common understanding in translanguaging studies that the languages used are not differentiated, but rather form an amorphous continuum in which speakers "soft-assemble" (Garcia 2009) and use available discursive resources as and when the social environment dictates. In other words, from the point of view of the speakers, multilinguals do not necessarily switch from one code to the next as studies on codeswitching tend to suggest (Gumperz 1982, Slabbert and MyersScotton 1996). Hence, the very notion of separated codes among multilinguals is challenged.

Secondly, the study has shown that blended ways of using language become creative in establishing rapport through greeting forms. Instead of using traditional greeting forms that characterise a specific language group, the speakers prefer more neutral forms that have historical roots in English or Afrikaans. We have seen that sho and $d a$, as discussed in section 
5.4, have become common kasi-taal distinguishing properties, which have no ethnic lineage to any of the African languages. Instead of using complete English words, the speakers creatively use semantic shifts as in "sure" for "certainly" to a contracted form that has expanded in meaning to include "hello" or "how are you?" The study has shown that these greeting usages make it harder to identify someone as speaking a particular African language. In doing so, the speakers resist mother-tongue labels of their heritage languages. Here, this practice shows that translanguaging speakers make decisions about who they want to become by choosing greeting forms that are not indexical of traditional language boundaries.

Although the kasi-taal speakers are fully enmeshed in their environment where they bridge linguistic gaps, the study has shown that they are constantly involved in transcultural imagination of the globalised world. The word nigger, used in complex ways to refer to African Americans, has found its way into the streets of Soweto, which may reflect transcultural identification with African Americans. While this lexical item has no history in Soweto, it appears that transcultural imagination takes precedence due to exposure to popular culture from the United States. Therefore, it should be stressed that, due to globalisation and the fast exchange of information in the $21^{\text {st }}$ century, languaging expressions are no longer attached to particular spaces and times. This is a typical example of linguistic mobility that is indexical of the permeability of boundaries between languages and cultures (Blommaert 2010, Creese and Blackledge 2010, Makoni 2003).

Another important finding of this study is with regard to experiential harmonisation of discretely defined Sotho languages. Mixed neighbourhoods of traditional users of three Sotho languages in the townships have brought these languages so close together that the kasi-taal speakers use them interchangeably when they communicate with one another. The study has shown that translanguaging between speakers of mutually intelligible languages is a natural process where these languages become indistinguishable in everyday use. While the translanguaging literature often refers to a mixture of non-cognate languages, here we saw an opportunity for using Sotho language varieties without boundaries. In previous studies, Sotho languages were classified as mutually intelligible to the extent that their orthographies could be harmonised or restandardised into a common form (Alexander 1989; Makalela 2005, 2009; Nhlapo 1944; Prah 1998). The kasi-taal languaging experience has thus revealed practical opportunities for harmonised use in hybrid communities such as the townships.

The idea of indistinguishable forms and traditional boundaries in African languages was revealed further through lexicalisation processes when kasi-taal borrows words from African languages, English and Afrikaans. Here, the study revealed that there are internal rules governing lexical formations when these languages come into contact in the townships. I have shown that there is a semantic shift that re-appropriates words in new, creative ways as speakers continuously shape their identities (as in the example of blome, where the Afrikaans word may be associated with flower gardens around homes where people sit and relax). I have also illustrated morphological rules where English root words follow regular derivational processes in which their original parts of speech are changed using the African languages' affixation system. While this is a normal process of lexical borrowing between non-cognate languages (cf. examples in Slabbert and Myers-Scotton 1996), what is perhaps salient is the similarity of the morphological conjugations in clustered African languages. This renders the newlyborrowed lexeme neutral for traditional speakers of three or four African languages. For example, lelecture would be generic to all Nguni languages, while ditheorists is generic to all 
Sotho languages. I referred to this phenomenon as "internal translanguaging", which takes advantage of similarities in the substrate systems of mutually intelligible African languages. It is in this context that kasi-taal usage predicts future harmonisation possibilities that transcend the linguistic boundaries between closely related languages.

\section{Conclusion}

This study has shown that townships around Johannesburg practice multilingualism in fluid, mobile and flexible ways that transcend traditional African language boundaries. As a result, designations such as "mother tongue" seem increasingly irrelevant to individuals from these areas who favour a hybrid form, kasi-taal, which involves a confluence of Afrikaans, English, Nguni and Sotho languages. From a translanguaging perspective, the speakers' linguistic repertoires have expanded to give them the flexibility to soft-assemble and make choices in their everyday encounters, such as when they are in monolingual situations. This languaging practice goes far beyond what has traditionally been referred to as "codeswitching", which often focuses on language interference (Hornberger and Link 2012). What we see instead is the way in which multilingual speakers tend to become socially versatile by actively making choices about who they want to become in fluid language context situations. In Garcia's (2011) terms, they identify through languaging.

The second major finding of this study is that kasi-taal is a rule-governed system that follows the regular semantic and morphological processes of contact language situations. In this case, morphological processes of affixation revealed an internal languaging system that converges kasi-taal usage across a wider spectrum of users of different languages which already share common grammatical rules. While at the surface this phenomenon reflects how kasi-taal speakers see themselves as a new generation of speakers who cannot be tied to a single linguistic and cultural code, it is worth noting that the transcultural and linguistic mobility of people in the $21^{\text {st }}$ century provide new opportunities to redefine languages. The small sample size of the study and its inherent limitation of reliance on self-reports do, however, call for more studies on this linguistic development from translanguaging, migration and settlement angles in order to draw comprehensive accounts of hybrid language use in the townships and comparable situations. This study forms a basis for future studies that need to take into account these hybrid forms of languaging and identity negotiation.

\section{Acknowledgement}

I wish to thank the two anonymous reviewers for their insightful comments and suggestions made to improve this paper.

\section{References}

Alexander, N. 1989. Language policy and national unity in South Africa/Azania. Cape Town: Buchu Books.

Baker, C. 2011. Foundations of bilingual education and bilingualism. Clevedon: Multilingual Matters. 
Blommaert, J. 2010. The sociolinguistics of globalization. Cambridge: Cambridge University Press.

Canagarajah, S. 2011. Codemeshing in academic writing: Identifying teachable strategies of translanguaging. Modern Language Journal 95: 401-417.

Creese, A. and A. Blackledge. 2010. Towards a sociolinguistics of superdiversity. Erziehungswiss 13: 549-572.

Garcia, O. 2009. Bilingual education in the $21^{\text {st }}$ century: A global perspective. Miden, MA: Wiley/Blackwell.

Garcia, O. 2011. From language garden to sustainable languaging: Bilingual education in a global world. Perspectives 34(1): 5-9.

Glaser, C. 1991. Bo-tsotsi: The youth gangs of Soweto, 1935-1976. Oxford: James Curry.

Gumperz, J. 1982. Discourse strategies. Cambridge: Cambridge University Press.

Heller, M. 2007. Bilingualism as ideology and practice. In M. Heller (ed.) Bilingualism: A social approach. Basingstoke: Palgrave. pp. 1-24.

Hornberger, N. and H. Link. 2012. Translanguaging and transnational literacies in multilingual classrooms: a biliteracy lens. International Journal of Bilingual Education and Bilingualism 15: $261-278$.

Kanno, P and B. Norton. 2003. Imagined communities and education possibilities: introduction. Journal of Language Identity and Education 2(4): 241-249.

Lindholm-Leary, K.J. 2001. Dual language education. Clevedon: Multilingual Matters.

Madiba, M. 2013. Promoting concept literacy through multilingual glossaries: A translanguaging approach. In C. Van der Walt and L. Hibbert (eds.) Multilingual teaching and learning in higher education in South Africa. Clevedon: Multilingual Matters. (Forthcoming).

Makalela, L. 2005. We speak eleven tongues: Reconstructing multilingualism in South Africa. In B. Brock-Utne and R. Hopson (eds.) Languages of instruction for African emancipation: Focus on postcolonial contexts and considerations. Cape Town: CASAS. pp. 147-174.

Makalela, L. 2009. Unpacking the language of instruction myth: Towards progressive language in education policies in Africa. In K. Prah and B. Brock-Utne (eds.) Multilingualism: An African advantage. Cape Town: Casas. pp. 170-194.

Makalela, L. 2013. Teaching indigenous African languages to speakers of other African languages: The effects of translanguaging for multilingual development. In C. Van der Walt and L. Hibbert (eds.) Multilingual teaching and learning in higher education in South Africa. Clevedon: Multilingual Matters. (Forthcoming). 
Makhudu, P.D.K. 2002. Introduction to Flaaitaal. In R. Mesthrie (ed.) Language in South Africa. Cambridge: Cambridge University Press. pp. 399-406.

Makoni, S. 2003. From misinvention to disinvention of language: Multilingualism and the South African Constitution. In S. Makoni, G. Smitherman, A. Ball, and A. Spears (eds.) Black linguistics: Language, society and politics in Africa and the Americas. London and New York: Routledge. pp. 132-149.

Makoni, S. and P. Mashiri. 2007. Critical historiography: Does language planning in Africa need a construct of language as part of its theoretical apparatus? In S. Makoni and A. Pennycook (eds.) Disinventing and reconstituting languages. Clevedon: Multilingual Matters. pp. 62-89.

Makoni, S. and A. Pennycook. (eds.) 2007. Disinventing and reconstituting languages. Clevedon, UK: Multilingual Matters.

Mignolo, W. 2000. Local histories/global designs. Coloniality, subaltern knowledges, and border thinking. Princeton: Princeton University Press.

Mesthrie, R. (ed.) 2002. Language in South Africa. Cambridge: Cambridge University Press.

Nhlapo, J. 1944. Bantu babel: Will the Bantu languages live? Cape Town: The African Bookman.

Ntshangase, D.K. 2002. Indaba yami i-straight: Language and language practices in Soweto. In R. Mesthrie (ed.) Language in South Africa. Cambridge: Cambridge University Press. pp. 407418.

Prah, K. 1998. Between extinction and distinction. Harmonization and standardization of African languages. Johannesburg: Witwatersrand University Press.

Shohamy, E. 2006. Language policy: Hidden agendas and new approaches. London: Routledge.

Slabbert, S and C. Myers-Scotton. 1996. The structure of Tsotsitaal and Iscamtho: Codeswitching and in-group identity in South African townships. Linguistics 34: 317-342.

Smitherman, G. 2000. Talkin that talk: Language, culture and education in African America. New York: Routledge.

Wei, L. 2011. Moment analysis and translanguaging space: Discursive construction of identities by multilingual Chinese youth in Britain. Journal of Pragmatics 43(5): 1222-1235. 